\title{
An unusual variant of malignant struma ovarii
}

\author{
J V Amalaseelan ${ }^{1}$ and K A Perera ${ }^{2}$
}

\section{Summary}

Struma ovarii is a highly specialised form of mature ovarian teratoma. When thyroid tissue constitutes $50 \%$ or more of the ovarian neoplasm, the tumour is termed struma ovarii [1]. Malignant struma ovarii is rare and makes up $0.1-0.3 \%$ of all ovarian teratomas [2]. We describe a case of follicular variant of papillary carcinoma arising from struma ovarii with elevated CA-125 and pseudo-Meig syndrome.

\section{Case report}

A 57-year old postmenopausal woman developed progressive generalised abdominal distension over three months. She was otherwise asymptomatic. Her medical and family history was unremarkable and there was no history of thyroid disease. On examination she was found to have gross ascites without any palpable abdominal masses. Vaginal and rectal examinations were normal. No thyroid enlargement was noticed. The CT-scan of the abdomen showed a mixed density illdefined mass in the region of left adnexae with ascites. Her routine blood investigations were normal. Thyroid function tests were not done preoperatively. Her CA125 level was over $500 \mathrm{u} / \mathrm{ml}$, and chest xray showed a small right-sided pleural effusion.

A provisional diagnosis of ovarian malignancy was made and total abdominal hysterectomy and bilateral salpingo-oophorectomy with omental biopsy was done. Apart from a multilocular left ovarian tumour and ascites no abnormalities were seen in the abdominal cavity.

Histological examination revealed a multicystic left ovary of $4 \times 5 \times 2 \mathrm{~cm}$ composed mainly of thyroid tissue. A small focus of thyroid carcinoma $(3 \mathrm{~mm})$ composed of follicles lined by overlapping optically clear nuclei was present. No papillae were noticed within the malignant component and mature cartilage was found within the ovary. A pathological diagnosis of follicular variant of papillary carcinoma was made. The right ovary showed mature cystic teratomas. Uterus, cervix, tubes and omental tissue did not reveal any pathological changes. Ascitic fluid was free of tumour cells.

Total thyroidectomy followed by ${ }^{131} \mathrm{I}$ ablation is the recommended treatment for malignant stuma ovarii.
However, we decided to manage this patient conservatively considering the small size of the malignant tumour. Thyroid function tests, chest xray, ultrasound abdomen and CA-125 $(7 \mathrm{u} / \mathrm{ml})$ one month after surgery were normal.

\section{Discussion}

Struma ovarii has elicited considerable interest among gynaecologists because of its many fascinating features. Its atypical presentation can rarely mimic a typical ovarian carcinoma. Many cases of stuma ovarii have been reported with elevated CA-125 level, ascites and hydrothorax (pseudo-Meig syndrome) [3, 4, 5, 6, $7,8]$. Only one case has shown malignant thyroid tissue and it has been reported as the first malignant struma ovarii patient with pseudo-Meig syndrome and elevated CA-125 [5].

The current criteria for pathological diagnosis of malignant struma ovarii include the same histological features used for the diagnosis of thyroid carcinoma such as "overlapping ground-glass nuclei" [1].The patient we describe also showed the typical groundglass histological pattern without papillary features, finally diagnosed as a follicular variant of papillary carcinoma.

Because of its rarity there was no consensus on the management of malignant struma ovarii. These patients have traditionally been treated with total abdominal hysterectomy and bilateral oophorectomy as for any other ovarian tumour. Thyroidectomy and ${ }^{131}$ I therapy have been given only if metastases or recurrence is detected [2]. These patients should be treated as if they had thyroid carcinoma rather than an ovarian carcinoma $[9,10]$. The patients treated conservatively after surgery were found to have higher rates of recurrence compared to those who got ${ }^{131} \mathrm{I}$ treatment as adjuvant $[2,10]$. Accordingly, all patients with malignant stuma ovarii should undergo total thyroidectomy followed by ${ }^{131} \mathrm{I}$ ablation to prevent relapse.

\section{References}

1. Devaney K, Snyder R, Norristtj, Tarassoli FA. Proliferative and malignant struma ovarii; a clinicopathological study of

${ }^{1}$ Registrar in Clinical Oncology, and ${ }^{2}$ Clinical Oncologist, National Cancer Institute, Maharagama, Sri Lanka. Correspondence: JVA, e-mail <julan_24@yahoo.com>. Received 31 October 2007 and revised version accepted 28 February 2008. Conflicts of interests: none declared. 
54 cases. International Journal of Gynaecological Pathology 1993; 12: 333-43.

2. Makani S, Kim W, Gaba AR. Struma ovarii with a focus of papillary thyroid carcinoma. A case report and a review of literature. Gynaecologic Oncology 2004; 94: 835-9.

3. Rim SY, Kim SM, Choi HS. Struma ovarii shows clinical characteristics of ovarian malignancy. International Journal of Gynaecological Cancer 2005; 15: 1156-9.

4. Huh JJ, Montz FJ, Bristow RE. Struma ovarii associated with pseudo-Meig syndrome and elevated serum CA-125. Gynaecologic Oncology 2002; 86: 231-4

5. Zannoni GF, Galkota V, Legge F, Tarquini E, Scambia G, et al Meig syndrome associated with malignant struma ovarii. Gynaecologic Oncology 2004; 94: 226-8.

6. Loizzi V, Cormio G, Resta L, Fattizzi N, Vicino M, Selvaggi L. Pseudo-Meig syndrome and elevated CA-125 associated with struma ovarii. Gynaecologic Oncology 2005; 97: 282-4.

7. Bokhari A, Rosenfeld GS, Cracchiolo B, Heller DS. Cystic stuma ovarii with ascites and elevated CA-125 level. The Journal of Reproductive Medicine 2003; 48: 52-6.

8. Bethune M, Quinn M, Rome R. Struma ovarii presenting as acute pseudo-Meig syndrome with an elevated CA-125 level. Australia and New Zealand Journal of Obstetrics and Gynaecology 1996; 36: 372-3.

9. Mattucci ML, Dellera A, Guerriero A, Barbieri F, Minnelli L, et al. Malignant struma ovarii: a case report and the review of the literature. Journal of Endocrinological Investigation 2007; 30: 517-20.

10. De Simone CP, Lele SM, Modesitt SC. Malignant struma ovarii: a case report and analysis of cases reported in the literature with focus on survival and ${ }^{131}$ I therapy. Gynaecologic Oncology 2003; 89: 543-8.

\section{The solitary reaper}

Will no one tell me what she sings?

Perhaps the plaintive numbers flow

For old, unhappy, far-off things,

And battles long ago:

Or is it more humble lay,

Familiar matter of to-day?

Some natural sorrow, loss, or pain,

That has been, and may be again?

Whate'er the theme, the maiden sang

As if her song could have no ending;

I saw her singing at her work,

And o'er the sickle bending;

I listened, motionless and still;

And, as I mounted up the hill,

The music in my heart I bore,

Long after it was heard no more.

William Wordsworth, English Poet. (1770-1850 AD) 